
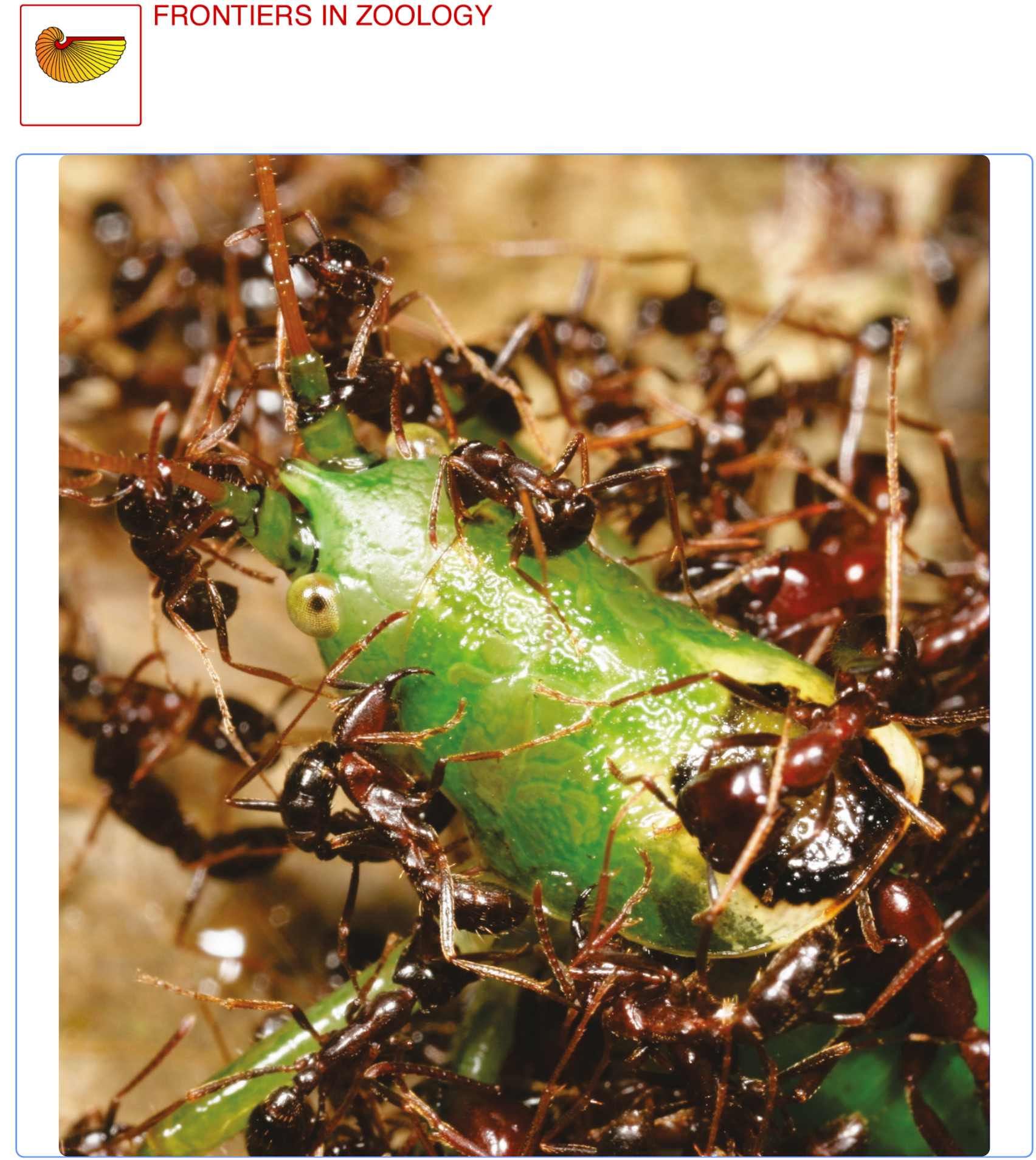

\title{
Hybridization in East African swarm-raiding army ants
}

Kronauer et al. 


\title{
Hybridization in East African swarm-raiding army ants
}

\author{
Daniel JC Kronauer ${ }^{1,2^{*}+}$, Marcell K Peters ${ }^{3,4+}$, Caspar Schöning ${ }^{1,5}$ and Jacobus J Boomsma ${ }^{1}$
}

\begin{abstract}
Background: Hybridization can have complex effects on evolutionary dynamics in ants because of the combination of haplodiploid sex-determination and eusociality. While hybrid non-reproductive workers have been found in a range of species, examples of gene-flow via hybrid queens and males are rare. We studied hybridization in East African army ants (Dorylus subgenus Anomma) using morphology, mitochondrial DNA sequences, and nuclear microsatellites.

Results: While the mitochondrial phylogeny had a strong geographic signal, different species were not recovered as monophyletic. At our main study site at Kakamega Forest, a mitochondrial haplotype was shared between a "Dorylus molestus-like" and a "Dorylus wilverthi-like" form. This pattern is best explained by introgression following hybridization between D. molestus and D. wilverthi. Microsatellite data from workers showed that the two morphological forms correspond to two distinct genetic clusters, with a significant proportion of individuals being classified as hybrids.

Conclusions: We conclude that hybridization and gene-flow between the two army ant species D. molestus and D. wilverthi has occurred, and that mating between the two forms continues to regularly produce hybrid workers. Hybridization is particularly surprising in army ants because workers have control over which males are allowed to mate with a young virgin queen inside the colony.
\end{abstract}

Keywords: Dorylinae, Formicidae, introgression, microsatellites, mtDNA, gene flow

\section{Background}

While botanists have long accepted that hybridization plays an important role in plant evolution and regularly leads to the emergence of new species [1], zoologists have traditionally regarded hybridization and interspecific gene flow as rare exceptions [2]. However, the advent of molecular genetic markers has changed this view during the last decade and it is now widely accepted that hybridization between closely related species is also common in animals [3-5]. Hybrids are often non-viable or sterile due to negative epistasis and therefore tend to be rather efficiently removed from the population by natural selection [6]. However, in situations where this is not the case, hybridization can lead to the collapse of closely related species into a single panmictic population

\footnotetext{
* Correspondence: dkronauer@rockefeller.edu

+ Contributed equally

${ }^{1}$ Centre for Social Evolution, Department of Biology, University of

Copenhagen, Universitetsparken 15, 2100 Copenhagen, Denmark

Full list of author information is available at the end of the article
}

[e.g. [7]], or to speciation events when some form of reproductive isolation between parental species and hybrids emerges [3-5].

In haplodiploid eusocial animals such as ants, the consequences of hybridization can be strikingly different from those in other organisms. First, a diploid queen that has mated with a heterospecific haploid male will still produce purebred sons via arrhenotokous parthenogenesis, so that hybrid males will only be produced in the F2 generation. Second, potentially negative consequences of hybrid sterility can be mitigated or even avoided when hybrid individuals mostly or exclusively become non-reproductive workers [8,9]. Hybrid workers do indeed regularly occur in a variety of ant species, whereas hybrid queens and males are normally not observed [10-12]. Hybridization in ants can therefore lead to interesting evolutionary novelties, such as genetic caste determination in interdependent lineages of Pogonomyrmex harvester ants, where purebred females become queens and interlineage hybrids become

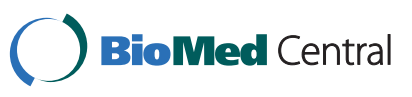

(c) 2011 Kronauer et al; licensee BioMed Central Ltd. This is an Open Access article distributed under the terms of the Creative Commons Attribution License (http://creativecommons.org/licenses/by/2.0), which permits unrestricted use, distribution, and reproduction in any medium, provided the original work is properly cited. 
workers $[13,14]$. Another recent example is a population of Formica wood ants with two clearly distinct male genepools and hybrid queens [15]. This stable system is maintained by strong transmission ratio distortion with respect to the sex of the offspring. In both cases there is no gene flow between the parental populations.

In the present study we investigated possible hybridization between different species of African swarm-raiding army ants, with particular focus on Kakamega Forest, Kenya, which is one of the few sites where the two closely related species, Dorylus (Anomma) molestus and Dorylus (Anomma) wilverthi, occur in sympatry. African swarm-raiding army ants (the "driver ants") are a prominent feature in afrotropical forests, where they are prime invertebrate predators with colony sizes of over ten million individuals. They form a well-supported clade within the Dorylus subgenus Anomma [16]. Like in other Hymenoptera, females (queens and workers) are diploid, while males are haploid and are produced by arrhenotokous parthenogenesis. Army ant queens, unlike the queens of most other ants, are permanently wingless, never go on a mating flight, and do not found new colonies independently. Instead, large colonies produce a reproductive brood of several thousand winged males and just a few virgin queens. Colony fission occurs when the mother queen and a large fraction of the worker-force emigrate from the nest and leave the developing reproductive brood and the remaining workers behind. All but one of the virgin queens are eliminated in yet unknown ways. After the males have eclosed, they disperse on the wing to mate with a young queen in another colony. Virgin queens, on the other hand, never leave their natal colony and mate with typically $10-30$ foreign males that enter the colony from outside [17]. Because colonies and their queens only disperse on foot, gene flow is highly male-biased $[18,19]$.

An interesting consequence of this idiosyncratic reproductive system is that males have to "run the gauntlet of the workers" before they can mate, so that workers have ample opportunities to choose the mates of their queen-sister [20]. If her later breeding success is affected by some of her many matings being heterospecific, the workers are under selection to influence the outcome of this mating process because the result affects their inclusive fitness. This implies that documentation of hybridization and introgression in army ants provides direct working hypotheses about the fitness of mixed genotypes. Dorylus colonies are headed by a single queen (monogynous), but due to the high queen-mating frequency, most workers in a colony are half-sisters, i.e. they have the same mother queen but different fathers [17].

Previous work showed that the two species at Kakamega occupy clearly distinct ecological niches, with $D$. wilverthi being essentially restricted to intact rainforest, while $D$. molestus also occurs in savannah habitats and open agricultural landscapes [21-23]. Our preliminary morphological assessments suggested that both populations at Kakamega are aberrant when compared to allopatric populations of the same species, indicating that hybridization and introgression may have taken place. That hybridization between closely related army ants may occur is also consistent with the observation that heterospecific males are occasionally found in Dorylus (Anomma) colonies [24], and with the description of the "hybrid variety" D. sjoestedti var. sjoestedti-wilverthi [25].

Here we use a combination of morphological, mitochondrial and nuclear genetic data to show that hybridization and introgression have occurred historically between different species of swarm-raiding army ants at a large geographic scale in East Africa, and that ongoing hybridization can be detected in Dorylus workers from Kakamega. Our results allow novel inferences about the evolutionary relevance of hybridization in social insects.

\section{Results}

\section{(a) Morphological Analysis}

The D. wilverthi-like workers from Kakamega (see Figure 1 for geographic positions of study sites) had the posterior angles of the head prolonged into a raised point, but not recurved outwards as in specimens from more western populations (Figure 2a). More than half of the examined $D$. molestus-like workers lacked the characteristic petiolar tubercles. Workers of both forms at Kakamega had relatively shorter antennal scapes than the workers from the respective "pure" allopatric populations (Figure 2b). The best common regression model for the morphometric data combined was SL $=0.3039$ * $\mathrm{HW}+0.6994(\mathrm{SL}=$ antennal scape length, $\mathrm{HW}=$ maximum head width). Differences between the relative residuals between all four groups were highly significant (Kruskal-Wallis statistic $=280.7, \mathrm{p}<0.0001$, Dunn's Multiple Comparison Test in all comparisons $\mathrm{p}<0.01$ ).

\section{(b) Phylogeographic Analysis}

The phylogenetic analysis of mitochondrial haplotypes resolved several well supported clades (Figures 3 and 4, Table 1). Most strikingly, neither D. molestus nor D. wilverthi were resolved as monophyletic. Instead, the mitochondrial phylogeny reflects geographical patterns rather than species affiliations: all samples from the coastal area of Kenya and Tanzania south of the Lower Tana River form a well-supported clade, extending inland to the southern slope of Mt. Kenya (clade 3 in Figures 3 and 4). The same is true for samples from Ethiopia and two of the more northern samples from Kenya and Uganda (clade 4). Samples north of and around Lake Victoria form another big clade (clade 2), which includes 


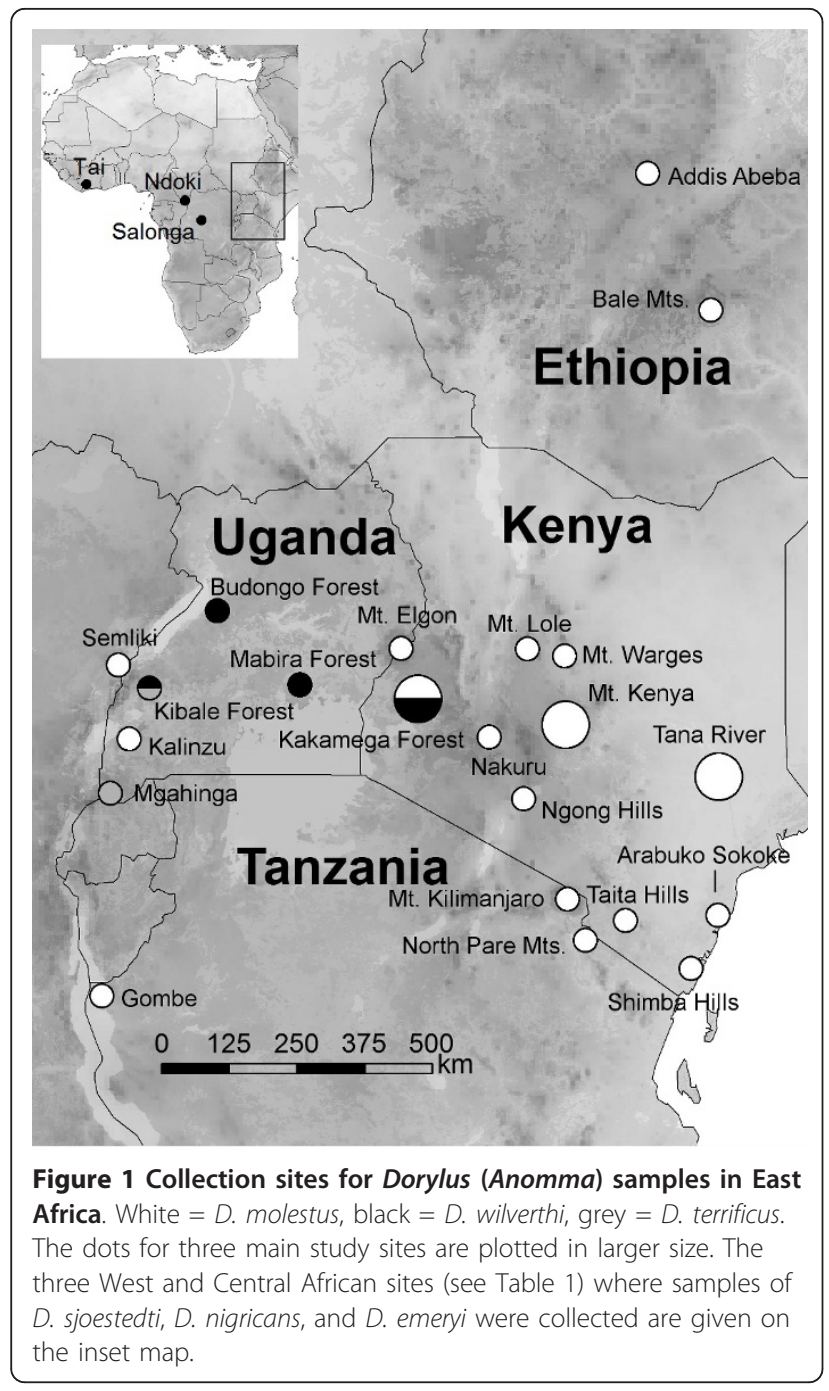

haplotypes from all three species that occur in the area. All common haplotypes from Kakamega form a monophyletic group (clade 1), which is nested within the larger Lake Victoria group (clade 2).

\section{(c) Population Structure and Divergence}

We assessed the population structure and divergence among three populations of D. molestus (Tana River, Mt. Kenya, Kakamega Forest) and one D. wilverthi population (Kakamega Forest). None of the pair-wise tests for genotypic disequilibrium between microsatellite markers was significant (all $\mathrm{p}>0.05$ ). Pair-wise estimates of genetic differentiation between four analysed populations at nuclear microsatellites $\left(F_{S T}\right)$ are given in Table 2. Estimates of $F_{S T}$ between the $D$. wilverthi-like and the D. molestus populations were slightly but consistently higher than estimates between the different $D$. molestus populations (Table 2; one-tailed $\mathrm{t}$-test: $\mathrm{t}=$ $-2.33, \mathrm{df}=4, \mathrm{p}=0.04)$.
The mitochondrial haplotype diversity was much lower in the $D$. wilverthi-like population $\left(N_{a}=2 ; R_{s}=\right.$ $1.55 ; \mathrm{N}=34$ ) than in the $D$. molestus populations (Kakamega: $N_{a}=7 ; R_{s}=6.24 ; \mathrm{N}=42 ;$ Mt. Kenya: $N_{a}=8 ; R_{s}$ = 6.94; $\mathrm{N}=29$; Tana River: $N_{a}=5 ; R_{s}=5.00 ; \mathrm{N}=11$ ). Interestingly, the $D$. wilverthi-like population was close to fixation (allele frequency $=0.97$ ) for a haplotype that was also common in the sympatric $D$. molestus-like population at Kakamega (allele frequency $=0.19$ ) and was closely related to the other local $D$. molestus haplotypes (Figures 3 and 4). At the same time this is the only haplotype that is shared between any of the four populations. The second rare haplotype found in D. wilverthi from Kakamega is closely related to the common haplotype and differs only by a single base-pair (Figure 4).

Replicate runs in STRUCTURE were highly consistent in every analysis. The highest likelihood scores were associated with a model with four subdivisions $(k=4$, mean $\ln L$ over five replicate runs $=-3185.36 ; 0.23 \mathrm{SD}$; for comparison: $k=2,-3409.86 ; 0.11 \mathrm{SD} ; k=3$, -3245.90; 0.28 SD; all $k>4$ had lower average likelihoods than $k=4$ ), although a model with five subdivisions had very similar likelihood scores $(k=5,-3185.56$; $0.81 \mathrm{SD})$. The four clusters corresponded well to the four populations, although a significant proportion of individuals had reasonably high likelihoods of ancestry in a population other than their source population (Figure 5; Table 2). By far the strongest uncertainty over individual assignments was found between the D. wilverthi-like and $D$. molestus-like populations at Kakamega Forest, as well as between the Mt. Kenya and Tana River populations of $D$. molestus. When set to divide the samples in two groups $(k=2)$, STRUCTURE consistently recovered one cluster consisting of the two Kakamega populations and another cluster consisting of $D$. molestus samples from Tana River and Mt. Kenya, rather than combining the three $D$. molestus populations. At $k$ $=3$, STRUCTURE split the two Kakamega populations, and at $k=5$ the Tana River + Mt. Kenya samples generally formed three clusters, while the two Kakamega clusters were retained (results not shown).

To quantify the proportion of hybrid workers at Kakamega, we arbitrarily classified individuals with an inferred proportion of ancestry $<0.9$ in the correct source population as hybrids. Each hybrid individual was then determined to be "shared" between its source population and the population in which it had the highest proportion of ancestry among the non-source populations. The proportions of individuals that are "shared" between each pair of populations are given in Table 2 . According to this estimate, $18.2 \%$ of the genotyped workers from Kakamega Forest were hybrids. If we lower the cut-off value for the inferred proportion of 


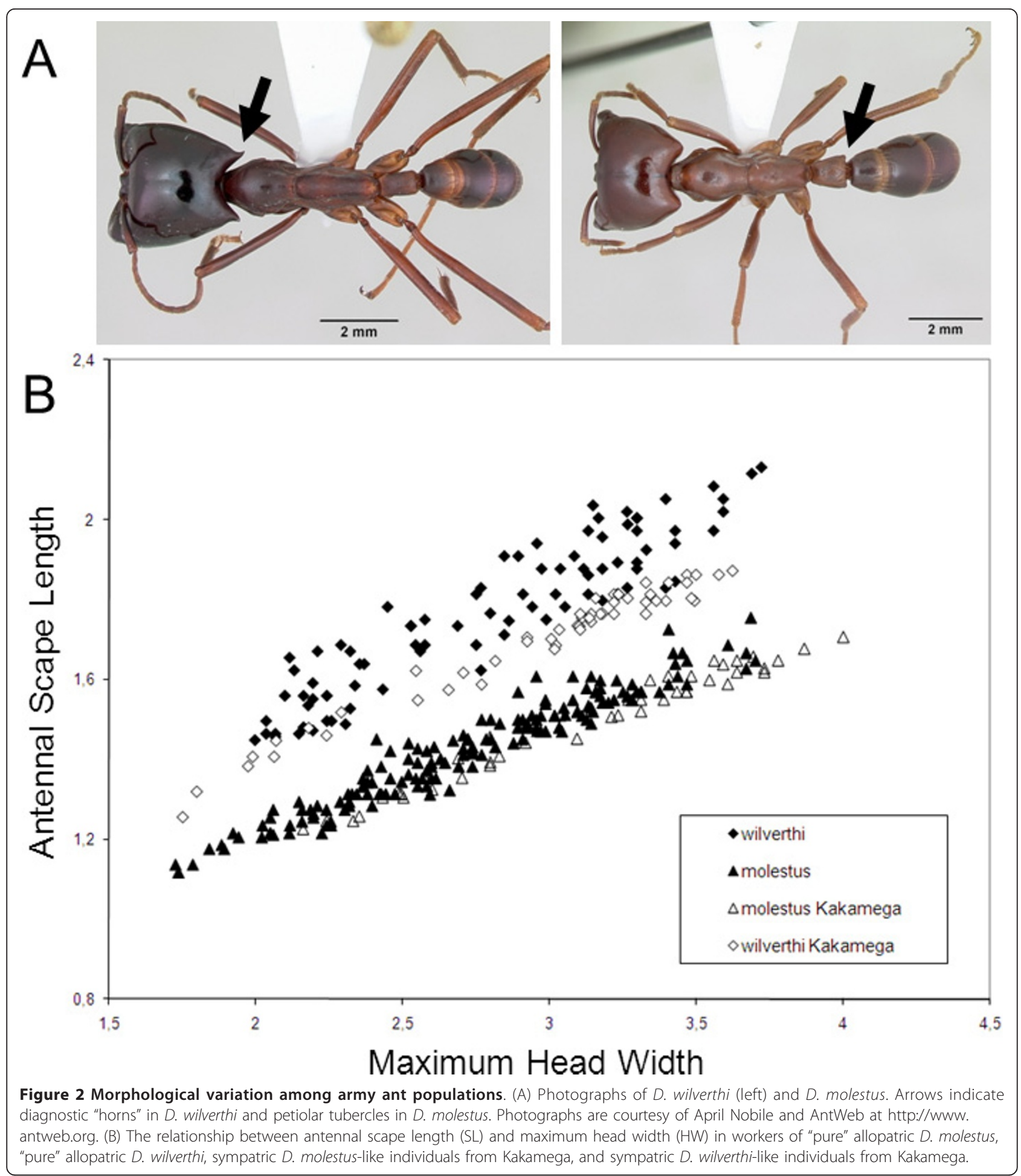

ancestry from 0.9 to 0.75 , still $7.3 \%$ of the Kakamega workers were hybrids (pairwise comparisons between all populations not shown).

Results from a GENECLASS2 analysis were fully consistent with the results obtained from STRUCTURE. Five $D$. wilverthi-like individuals were assigned to the $D$. molestus-like population from Kakamega (the D. molestus-like population from Kakamega had the highest probability of being the source population among the four potential source populations), and one D. molestuslike worker from Kakamega was assigned to the D. wilverthi-like population. Similarly, two D. molestus 


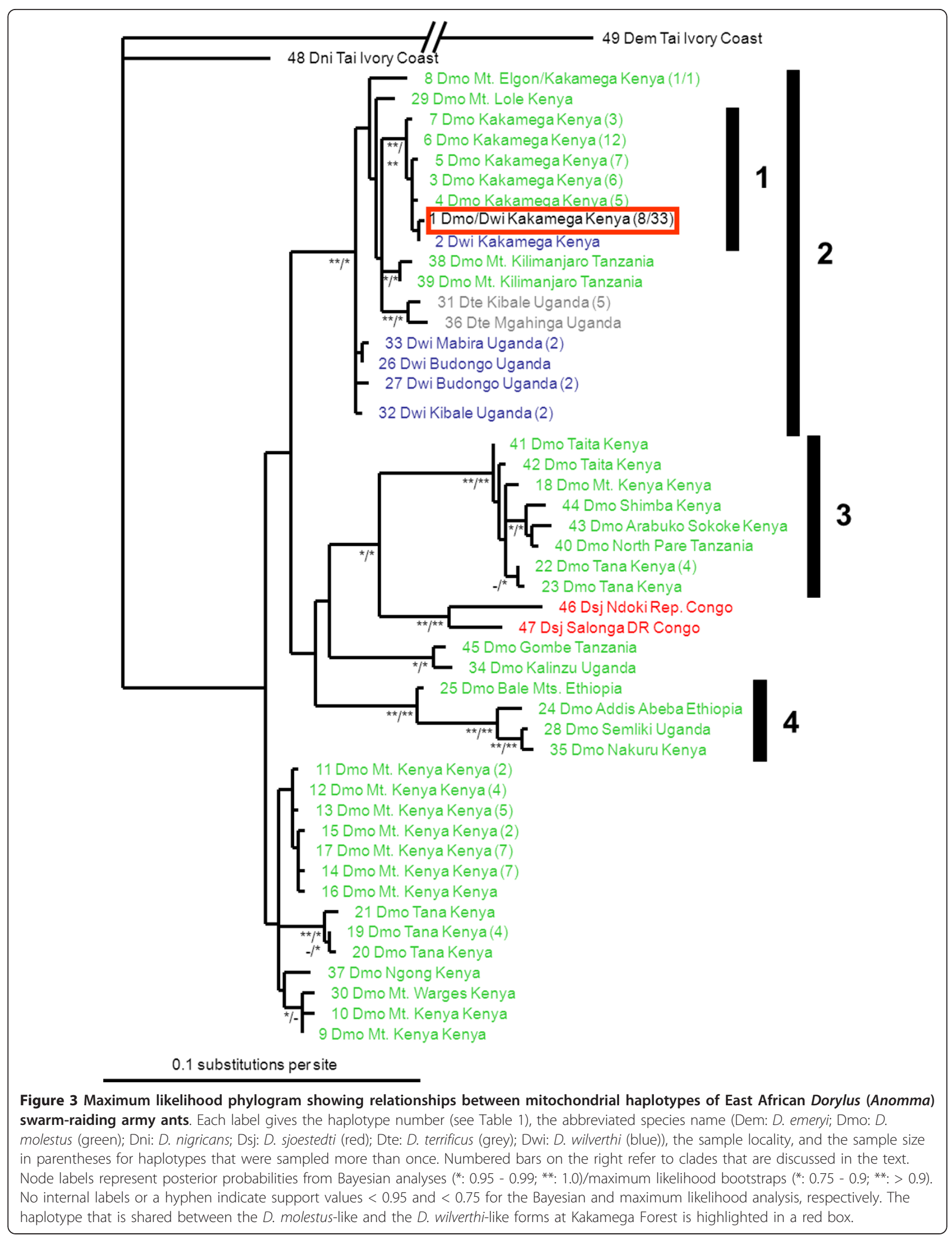




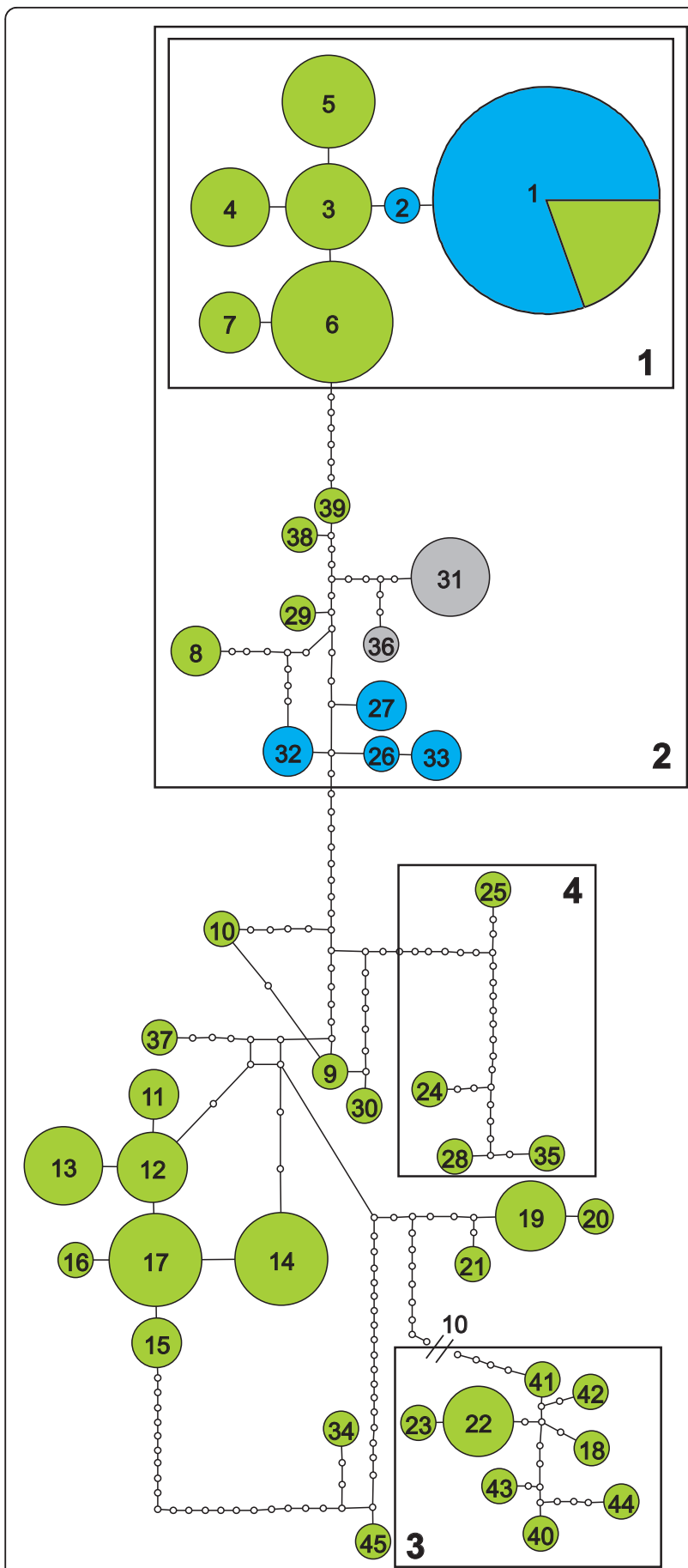

Figure 4 Parsimony network of all East African haplotypes of $D$. molestus, $D$. wilverthi and $D$. terrificus. A connecting line between haplotypes represents one mutation and small open circles represent missing (inferred) haplotypes. Green haploytypes are from D. molestus, blue haplotypes from D. wilverthi, and grey haplotypes from $D$. terrificus. Size of haplotype disks is proportional to their frequencies. Boxes with numbers indicate the same haplotype clusters as shown in Figure 3. workers from Mt. Kenya were assigned to the Tana River population, and six workers from Tana River were assigned to the Mt. Kenya population. No other crossassignments were found.

\section{Discussion}

\section{(a) Morphological analysis}

The morphological and morphometric data show that two forms of swarm-raiding army ants can be distinguished at Kakamega Forest. These two forms strongly resemble $D$. molestus and $D$. wilverthi from allopatric populations, but are also significantly different from "pure" D. molestus and D. wilverthi with intermediate phenotypes for several key characters (Figure 2). This suggests that both forms have arisen from hybridization between $D$. molestus and D. wilverthi at Kakamega Forest. At the same time, gene-flow has not been sufficient to completely collapse the two species into a single homogeneous hybrid population.

\section{(b) Mitochondrial phylogeny and introgression}

While mitochondrial haplotypes are clearly structured according to geographic origin (Figures 3 and 4), different Dorylus (Anomma) species are not generally recovered as monophyletic. Below we argue that this finding is best explained by the combined effects of unrecognized cryptic diversity within $D$. molestus and a complex history of mitochondrial introgression in the Lake Victoria region. D. molestus haplotypes tend to cluster into several well supported shallow clades, which are connected to other such clades by deeper branches (Figure 3). Furthermore, the Central African D. sjoestedti samples cluster with D. molestus samples from coastal Kenya and Tanzania, a finding that cannot be explained by introgression due to the large geographic distances and the fact that more western samples of $D$. molestus do not have haplotypes similar to those of $D$. sjoestedti. Incomplete lineage sorting seems similarly unlikely as an explanation (see below), so that this overall pattern is suggestive of unrecognized cryptic diversity within $D$. molestus.

The fact that identical or very similar haplotypes are shared between different species in spatially close populations around Lake Victoria, on the other hand, points towards a complex history of mitochondrial introgression in this narrower geographic area. The most striking example is found at Kakamega Forest, where the D. wilverthi-like form is close to fixation for a haplotype that is also frequent in the D. molestus-like form. This haplotype is nested within the clade of Kakamega D. molestus haplotypes (clade 1 in Figure 3). The clade of mitochondrial haplotypes from Kakamega Forest is in turn nested 
Table 1 List of unique mitochondrial COII haplotypes included in this study

\begin{tabular}{|c|c|c|c|c|}
\hline Haplotype no. & GenBank acc. no. & Species & Locality & $N$ colonies \\
\hline 1 & GQ999016 & D. wilverthi & Kakamega Forest, Kenya & 33 \\
\hline 1 & GQ999023 & D. molestus & Kakamega Forest, Kenya & 8 \\
\hline 2 & GQ999019 & D. wilverthi & Kakamega Forest, Kenya & 1 \\
\hline 3 & GQ999017 & D. molestus & Kakamega Forest, Kenya & 6 \\
\hline 4 & GQ999020 & D. molestus & Kakamega Forest, Kenya & 5 \\
\hline 5 & GQ999022 & D. molestus & Kakamega Forest, Kenya & 7 \\
\hline 6 & GQ999018 & D. molestus & Kakamega Forest, Kenya & 12 \\
\hline 7 & GQ999021 & D. molestus & Kakamega Forest, Kenya & 3 \\
\hline 8 & GQ999024 & D. molestus & Kakamega Forest, Kenya & 1 \\
\hline 8 & GQ999043 & D. molestus & Mt. Elgon, Kenya & 1 \\
\hline 9 & GQ999042 & D. molestus & Mt. Kenya (West), Kenya & 1 \\
\hline 10 & EF413797 & D. molestus & Mt. Kenya (East), Kenya & 1 \\
\hline 11 & GU065701 & D. molestus & Mt. Kenya (East), Kenya & 2 \\
\hline 12 & GU065703 & D. molestus & Mt. Kenya (East), Kenya & 4 \\
\hline 13 & GU065698 & D. molestus & Mt. Kenya (East), Kenya & 5 \\
\hline 14 & GU065699 & D. molestus & Mt. Kenya (East), Kenya & 7 \\
\hline 15 & GU065702 & D. molestus & Mt. Kenya (East), Kenya & 2 \\
\hline 16 & GU065704 & D. molestus & Mt. Kenya (East), Kenya & 1 \\
\hline 17 & GU065700 & D. molestus & Mt. Kenya (East), Kenya & 7 \\
\hline 18 & GQ999037 & D. molestus & Mt. Kenya (South), Kenya & 1 \\
\hline 19 & GQ999050 & D. molestus & Tana River (East), Kenya & 4 \\
\hline 20 & GQ999052 & D. molestus & Tana River (East), Kenya & 1 \\
\hline 21 & GQ999049 & D. molestus & Tana River (West), Kenya & 1 \\
\hline 22 & GQ999032 & D. molestus & Tana River (West), Kenya & 4 \\
\hline 23 & GQ999051 & D. molestus & Tana River (West), Kenya & 1 \\
\hline 24 & GQ999027 & D. molestus & Addis Abeba, Ethiopia & 1 \\
\hline 25 & GQ999028 & D. molestus & Bale Mts., Ethiopia & 1 \\
\hline 26 & GQ999040 & D. wilverthi & Budongo Forest, Uganda & 1 \\
\hline 27 & GQ999035 & D. wilverthi & Budongo Forest, Uganda & 2 \\
\hline 28 & GQ999031 & D. molestus & Semliki, Uganda & 1 \\
\hline 29 & GQ999053 & D. molestus & Mt. Lole, Kenya & 1 \\
\hline 30 & GQ999045 & D. molestus & Mt. Warges, Kenya & 1 \\
\hline 31 & EF413804 & D. terrificus & Kibale Forest, Uganda & 5 \\
\hline 32 & EF413798 & D. wilverthi & Kibale Forest, Uganda & 2 \\
\hline 33 & GQ999034 & D. wilverthi & Mabira Forest, Uganda & 2 \\
\hline 34 & GQ999030 & D. molestus & Kalinzu, Uganda & 1 \\
\hline 35 & GQ999033 & D. molestus & Nakuru, Kenya & 1 \\
\hline 36 & GQ999039 & D. terrificus & Mgahinga, Uganda & 1 \\
\hline 37 & GQ999038 & D. molestus & Ngong Hills, Kenya & 1 \\
\hline 38 & GQ999046 & D. molestus & Kilimanjaro, Tanzania & 1 \\
\hline 39 & GQ999047 & D. molestus & Kilimanjaro, Tanzania & 1 \\
\hline 40 & GQ999048 & D. molestus & North Pare, Tanzania & 1 \\
\hline 41 & GQ999029 & D. molestus & Taita Hills, Kenya & 1 \\
\hline 42 & GQ999044 & D. molestus & Taita Hills, Kenya & 1 \\
\hline 43 & GQ999041 & D. molestus & Arabuko Sokoke, Kenya & 1 \\
\hline 44 & GQ999025 & D. molestus & Shimba Hills, Kenya & 1 \\
\hline 45 & GQ999026 & D. molestus & Gombe, Tanzania & 1 \\
\hline 46 & EF413795 & D. sjoestedti & Ndoki, Republic of Congo & 1 \\
\hline 47 & GQ999054 & D. sjoestedti & Salonga, DR Congo & 1 \\
\hline 48 & EF413803 & D. nigricans & Tai, Ivory Coast & 1 \\
\hline 49 & EF413773 & D. emeryi & Tai, Ivory Coast & 1 \\
\hline
\end{tabular}

Haplotypes that were sampled in different species (haplotype 1) or in different populations of the same species (haplotype 8) are listed twice. 
Table 2 Genetic differentiation between three populations of D.molestus and one sympatric population of $D$. wilverthi

\begin{tabular}{|c|c|c|c|c|}
\hline & \multicolumn{3}{|c|}{ D. molestus } & \multirow{2}{*}{$\begin{array}{l}\text { D. wilverthi } \\
\text { 4. Kakamega }\end{array}$} \\
\hline & 1. Mt. Kenya & 2. Tana River & 3. Kakamega & \\
\hline 1. & - & 0.05 & 0.11 & 0.14 \\
\hline 2. & 48.9 & - & 0.12 & 0.16 \\
\hline 3. & 1.9 & 4.1 & - & 0.14 \\
\hline 4. & 3.8 & 1.0 & 18.2 & - \\
\hline
\end{tabular}

Above diagonal: Pair-wise genetic differentiation measured as $F_{S T}$. All estimates are significantly different from zero $(p<0.05)$ after standard Bonferroni correction for multiple comparisons. Below diagonal: The percentage of individuals that were classified as hybrids (individuals with an inferred proportion of ancestry $<0.9$ in the correct source population) and "shared" between each pair of populations according to the STRUCTURE analysis (see main text for details).

within a larger clade of haplotypes from the Lake Victoria region (clade 2 in Figure 3), which contains additional haplotypes from $D$. molestus, $D$. terrificus, and $D$. wilverthi. This pattern indicates a complex history of repeated mitochondrial introgression between different pairs of species.

The combination of two main factors makes it difficult to determine the original source species of the Lake Victoria haplotypes: 1 . We presently lack haplotype information for populations of $D$. wilverthi and D. terrificus that have clearly not undergone mitochondrial introgression, i.e. we are missing "true" $D$. wilverthi and $D$. terrificus haplotypes in our analysis. 2. Mitochondrial DNA undergoes frequent selective sweeps, and recurrent sweeps are likely to mask previous introgression events $[26,27]$.

During Pleistocene and Holocene glacial cycles $[28,29]$, the Lake Victoria region has seen recurrent expansions and retractions of forest and savannah habitat [30-32], so it is safe to assume that the distributional ranges of rainforest specialists like $D$. wilverthi and savannah/forest generalists like D. molestus have changed accordingly. The two species probably broadly overlapped during glacial periods of maximum forest expansion, when Kakamega Forest was connected to Ugandan rainforests [30], while $D$. wilverthi has been restricted to forest islands during interglacial periods as is the case at present. Given this complex recent biogeographic history, it will also be challenging to associate the observed cases of introgressive hybridization with discrete historic events.

It is interesting to note that only a single mitochondrial haplotype is shared between the two forms at Kakamega, while essentially all other haplotypes are restricted to the $D$. molestus-like form. One possible explanation is that mitochondrial gene-flow at Kakamega goes back to a single or very few events, which by chance involved only that particular haplotype. Alternatively, the pattern could be explained by selection. For example, all other D. molestus-like haplotypes, or potential cytoplasmic factors coupled to those haplotypes (like Wolbachia infections [33]), might have epistatic incompatibilities with parts of the $D$. wilverthi nuclear genome. That the reduced mitochondrial diversity in the $D$. wilverthi-like form at Kakamega is simply due to a recent genetic bottleneck seems unlikely because diversity at nuclear microsatellite loci is not reduced compared to other populations (Table 3).

Another noteworthy case of apparent mitochondrial introgression was found in the population from Tana River, where haplotypes from both sides of the river tend to cluster in clearly distinct clades (Figures 3 and 4) although, according to microsatellite data (see below), all samples belong to a single population. This suggests that at least one side of the river has captured haplotypes from a more distantly related $D$. molestus clade. This strong genetic structure at the maternally inherited mitochondrial locus, and a lack thereof at biparentally

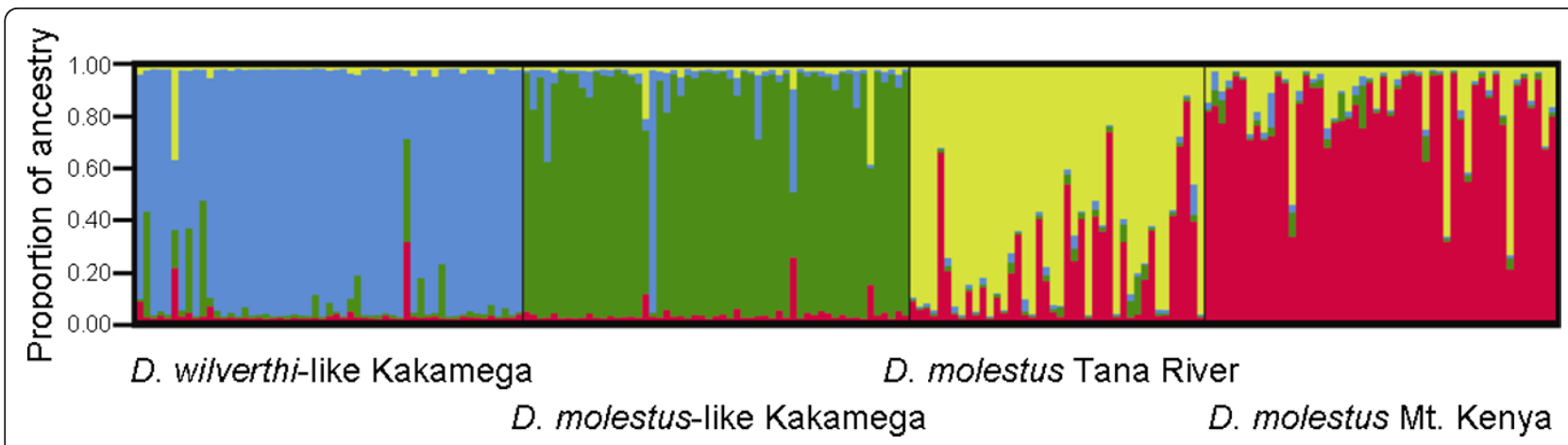

Figure 5 Assignment of individuals to four populations using the program STRUCTURE without $a$ priori assumptions. Shown are assignments of individuals from the D. wilverthi-like population at Kakamega Forest, the D. molestus-like population at Kakamega Forest, and the pure D. molestus populations at Tana River and Mt. Kenya. The y-axis represents the proportion of each multilocus genotype that is attributable to each of the four populations. Samples are grouped along the $\mathrm{x}$-axis according to their population of origin. 
inherited nuclear loci, stems from the fact that the permanently wingless army ant queens cannot cross water barriers, while the winged males readily do so [18].

Alternative explanations for a lack of monophyly between closely related species usually involve the retention of ancestral polymorphisms or incomplete lineage sorting. However, these mechanisms are less likely to apply to mtDNA as compared to nuclear DNA because ancestral polymorphisms will be lost more quickly due to genetic drift given the smaller effective population size of mtDNA and because mtDNA in insects evolves significantly faster than nuclear DNA (e.g. [34]). On the other hand, mtDNA seems to be particularly prone to introgression, at least in species where males are the heterogametic or haploid sex (e.g. [34-37]). One reason for this is that in such species males tend to suffer more from hybridization than females (Haldane's rule; [38]), so that gene-flow will be more restricted at nuclear loci relative to maternally inherited mitochondrial loci. Furthermore, if incomplete lineage sorting occurs at random it should not produce an obvious correlation with geographic distribution (e.g. [39]), as we observed in East African Dorylus (Anomma) species. Under incomplete lineage sorting, the minimum divergence time between sequences is given by the time elapsed since speciation [40]. In the absence of gene flow, mutations should therefore accumulate quickly in cytochrome oxidase II haplotypes, which have high mutation rates of ca. $1.5 \%$ per million years in insects (e.g. [41]). Given the strong geographic signal in our mtDNA phylogeny (Figures 3 and 4), the general lack of overlapping haplotypes between neighbouring conspecific populations, and the fact that sympatric species at Kakamega share identical haplotypes for fast evolving mitochondrial genes, we conclude that introgressive hybridization between army ant species is clearly the best explanation for the observed haplotype distribution in the Lake Victoria area.

\section{(c) Differentiation and hybridization at nuclear DNA}

The two morphological forms at Kakamega Forest can be clearly distinguished based on the nuclear microsatellite loci. This again shows that species boundaries have not become completely blurred, which would be expected if gene flow had been significant over extended periods of time. On the other hand, despite genetic differentiation among species being consistently higher than between conspecific populations (Table 2), a large proportion of workers at Kakamega could not be unequivocally assigned to one of the two forms by either STRUCTURE or GENECLASS2 (Figure 5). At the same time, pair-wise assignments between populations were far less problematic, even in conspecific comparisons. The only exception was the Tana River/Mt. Kenya comparison, which showed very weak differentiation making assignments difficult. The reason for this genetic similarity may well be that these two populations were connected via contiguous gallery forests along the Tana River until the recent past. Overall, this implies that a considerable proportion of workers at Kakamega Forest are hybrids between $D$. molestus and $D$. wilverthi.

\section{Conclusions}

This study provides conclusive evidence that introgressive hybridization has occurred between different Dorylus (Anomma) species. This is one of the few cases of documented gene flow between species of eusocial Hymentoptera ([11]; but see $[42,43]$ for other recent examples) and shows that reproductive isolation between species of East African swarm-raiding army ants is incomplete. The frequent occurrence of hybrid workers at Kakamega means that the two local forms still mate regularly today. However, it is important to keep in mind that hybrid workers do not necessarily translate into gene flow, because social insect workers normally do not reproduce. This also applies to Dorylus (Anomma) [19,44]. The general notion that hybrid workers are common between several pairs of closely related ant species, while hybrid queens and males are extremely uncommon [11], might explain why the two forms at Kakamega have retained their distinct morphology and ecological niche space, instead of having collapsed into a single homogeneous hybrid population. Hybridization in army ants is particularly surprising because, unlike in most social insects where mating occurs outside the nest, workers have control over which males obtain access to a virgin queen. Therefore, if hybridization would imply reduced colony fitness, workers should be under strong selection to recognize heterospecific males and prevent them from mating. This suggests that hybridization in army ants entails little or no fitness costs or might even be adaptive under certain circumstances. Future work will have to investigate the stability of the hybrid zone at Kakamega over time, and the effects of hybridization on the actual genotypes of Dorylus queens and males, to clarify the precise pattern of hybridization and the amount of ongoing gene-flow between the two sympatric forms.

\section{Materials and methods}

\section{(a) Sampling and morphological analysis}

To study patterns of mitochondrial differentiation between species and populations of East African Dorylus (Anomma) army ants, we collected 151 colony samples (one individual per colony) for mitochondrial DNA sequencing from 24 localities, representing four morphologically distinguishable species, $D$. molestus, Dorylus sjoestedti, Dorylus terrificus, and D. wilverthi (Figure 1; 
Table 1). A single West African sample of Dorylus nigricans was also included. A haplotype of the West African species Dorylus emeryi served as outgroup, as this species belongs to the sister clade of the swarm-hunting Anomma "driver ants" [16].

Samples for microsatellite genotyping (one worker per colony) were collected from four populations at three different sites in Kenya: Kakamega Forest (where $D$. molestus-like and $D$. wilverthi-like forms are sympatric; $\mathrm{N}=55$ each), the eastern slope of Mt. Kenya (D. molestus; $\mathrm{N}=50$ ), and Lower Tana River (D. molestus; $\mathrm{N}=$ 42). Subsets of these samples were also sequenced for mitochondrial DNA (see Table 1). The Mt. Kenya population is geographically situated halfway in between the two other populations (Figure 1). All samples were collected and stored in ethanol.

We identified samples morphologically using the diagnostic criteria given in the original species descriptions and in [45]. Furthermore, samples were directly compared with type specimens. D. molestus, D. terrificus, and $D$. sjoestedti, which currently have the status of subspecies of $D$. nigricans, were treated as species according to $[45,46]$, and the results of an ongoing taxonomic revision of the Dorylus (Anomma) swarm-raiding army ants (C. Schöning et al. unpublished). Importantly, D. wilverthi and $D$. molestus workers are easily distinguished: $D$. wilverthi workers have the posterior angles of the head uniquely prolonged into a raised, slightly outwardly recurved point ("horns"; Figure 2a), while D. molestus workers have posteroventral extensions ("tubercles") on the petiole (Figure 2a) and significantly shorter appendages than $D$. wilverthi $[47,48]$. To quantify morphological variation we measured antennal scape length (SL) in relation to maximum head width (HW) for large workers $(\mathrm{HW}>1.5 \mathrm{~mm})$ in four groups: D. molestus-like individuals from Kakamega $(\mathrm{N}=54$ workers from 10 colonies), $D$. wilverthi-like individuals from Kakamega ( $\mathrm{N}=45$ workers from nine colonies), "pure" allopatric D. molestus ( $\mathrm{N}=157$ workers from 31 colonies belonging to 20 populations across the species' range), and "pure" allopatric D. wilverthi $(\mathrm{N}=85$ workers from 16 colonies belonging to 10 populations across the species' range). Measurements were taken with a MS5 Leica stereomicroscope fitted with an ocular micrometer. Data were analysed following Schöning et al. [47].

\section{(b) DNA extraction, amplification, sequencing, and microsatellite genotyping}

DNA for sequencing was extracted from 1-2 worker legs using standard QIAGEN ${ }^{\circledR}\left(\right.$ DNeasy $\left.^{\circledR}\right)$ and MACHEREYNAGEL (Nucleo Spin ${ }^{\circledR}$ Tissue) kits. A mitochondrial fragment of the cytochrome oxidase II (COII) gene was amplified and sequenced using primers tRNALeu [16] and Barbara [49] as has been described earlier [16].
Sequencing reactions were either performed in house or purified PCR products were sent to a commercial sequencing facility (Macrogen, Korea). The final alignment used in this study consisted of 548 bp of COII sequence. GenBank accession numbers and details for sequenced samples are given in Table 1.

DNA for microsatellite genotyping was extracted by boiling 1-2 worker legs in $100 \mu \mathrm{l}$ of $5 \%$ Chelex 100 (BioRad). A total of 202 individuals were genotyped at five microsatellite loci (DmoB, DmoC, DmoD, DmoG, DmoO) as has been described previously [50].

\section{(c) Phylogeographic Analyses}

Phylogenetic analyses of mitochondrial sequences were conducted in a Bayesian framework using the program MrBayes 3.1.2 [51,52], and in a maximum likelihood framework using the program GARLI 0.96 [53]. We implemented a general time reversible model with gammadistributed rate heterogeneity $(\mathrm{GTR}+\mathrm{G})$, which was selected as the most appropriate model for our data by both hierarchical Likelihood Ratio Tests and the Akaike Information Criterion in MrModeltest 2.3 [54].

To assure convergence of Markov Chain Monte Carlo runs in MrBayes we repeated the analysis from two independent starting trees. One cold and three heated chains were run in parallel for $20^{*} 10^{6}$ generations and trees were sampled every 100 generations. Average standard deviations of split frequencies were consistently < 0.01 after $13^{*} 10^{6}$ generations, indicating that the independent runs had converged. Accordingly, the first 130,000 trees from each run were discarded as burn-in. Based on this sample of 140,002 trees from both runs combined, all potential scale reduction factors for model parameters were $<1.02$, indicating effective sampling from the posterior probability distribution. A consensus phylogram with posterior probabilities based on both runs was calculated in MrBayes.

We initially performed three independent runs in GARLI setting the number of generations after which the run is terminated if no new significantly better scoring topology has been found to 30,000, and otherwise using default parameter settings. We then performed a run with 1,000 bootstrap replicates setting the above parameter at 10,000.

A mitochondrial haplotype network for all East African haplotypes of D. molestus, D. wilverthi and D. terrificus was constructed using a statistical parsimony approach [55] implemented in TCS version 1.21 [56]. The connection limit in the TCS program was set at unlimited.

\section{(d) Population Structure and Divergence}

The number of alleles per microsatellite locus $\left(N_{a}\right)$, expected heterozygosity $\left(H_{s}\right)$, allelic richness corrected 
Table 3 Number of alleles $\left(N_{a}\right)$, expected heterozygosity $\left(H_{s}\right)$, allelic richness $\left(\boldsymbol{R}_{s}\right)$, and inbreeding coefficient $\left(\boldsymbol{F}_{I S}\right)$ estimated for five microsatellite loci and three populations of D.molestus and one sympatric population of $D$. wilverthi

\begin{tabular}{|c|c|c|c|c|c|c|c|c|c|c|c|c|c|c|c|c|}
\hline \multirow[b]{3}{*}{ Locus } & \multicolumn{12}{|c|}{ D. molestus } & \multirow{2}{*}{\multicolumn{4}{|c|}{$\begin{array}{c}\text { D. wilverthi } \\
\text { Kakamega } \\
(\mathrm{N}=55)\end{array}$}} \\
\hline & \multicolumn{4}{|c|}{$\begin{array}{l}\text { Mt. Kenya } \\
(\mathrm{N}=50)\end{array}$} & \multicolumn{4}{|c|}{$\begin{array}{c}\text { Tana River } \\
(\mathrm{N}=42)\end{array}$} & \multicolumn{4}{|c|}{$\begin{array}{c}\text { Kakamega } \\
(\mathrm{N}=55)\end{array}$} & & & & \\
\hline & $N_{a}$ & $H_{s}$ & $R_{s}$ & $F_{I S}$ & $N_{a}$ & $H_{s}$ & $R_{s}$ & $F_{I S}$ & $N_{a}$ & $H_{s}$ & $R_{s}$ & $F_{I S}$ & $N_{a}$ & $H_{s}$ & $R_{s}$ & $F_{I S}$ \\
\hline$\overline{D m o B}$ & 4 & 0.56 & 3.82 & -0.18 & 3 & 0.55 & 3.00 & 0.09 & 5 & 0.65 & 4.97 & 0.05 & 7 & 0.55 & 6.84 & 0.04 \\
\hline DmoC & 4 & 0.57 & 4.00 & 0.07 & 5 & 0.68 & 5.00 & 0.28 & 5 & 0.69 & 5.00 & 0.11 & 4 & 0.52 & 3.75 & 0.23 \\
\hline DmoD & 5 & 0.77 & 5.00 & -0.05 & 8 & 0.85 & 8.00 & -0.04 & 8 & 0.81 & 7.49 & 0.02 & 7 & 0.74 & 6.67 & 0.14 \\
\hline DmoG & 11 & 0.86 & 10.46 & $0.19^{*}$ & 12 & 0.86 & 11.98 & 0.11 & 9 & 0.82 & 8.49 & -0.02 & 6 & 0.72 & 6.00 & -0.04 \\
\hline DmoO & 9 & 0.86 & 8.97 & $0.26^{*}$ & 8 & 0.71 & 7.95 & 0.07 & 9 & 0.77 & 8.99 & -0.04 & 9 & 0.79 & 8.67 & 0.10 \\
\hline mean & 6.6 & 0.72 & 6.45 & 0.06 & 7.2 & 0.73 & 7.19 & 0.10 & 7.2 & 0.75 & 6.99 & 0.02 & 6.6 & 0.66 & 6.39 & 0.09 \\
\hline
\end{tabular}

$F_{I S}$ estimates significantly different from zero ( $p<0.05$ after standard Bonferroni correction for multiple comparisons) are marked with an asterisk.

for sample size $\left(R_{s}\right)$, and the inbreeding coefficient $F_{I S}$ were estimated for each population using the program FSTAT 2.9.3.2 [57]. $F_{I S}$ was tested for significant deviation from zero using 400 randomisations to assess Hardy Weinberg equilibrium. The same program was used to test for genotypic disequilibrium between all pairs of microsatellite loci within each population (Table 3). Furthermore, we used FSTAT to calculate pair-wise $F_{S T}$ as an estimate of genetic differentiation at microsatellite loci between populations and species. FSTAT was also used to calculate $N_{a}$ and $R_{s}$ for mitochondrial haplotypes.

We used two different model-based Bayesian methods to study hybridization between $D$. molestus and $D$. wilverthi at Kakamega. First, the clustering method of the program STRUCTURE 2.2 [58] was used to infer population structure at microsatellite loci without prior information on species assignments based on sample locality and morphology. The data from all four populations were combined in this analysis. To assure convergence and consistency of results, we conducted five replicate runs with different random seeds for each $k$, the number of subdivisions, ranging from one to 10 , under an admixture model with correlated allele frequencies [59]. Markov chains were run for $10^{6}$ generations and the first $10^{5}$ generations were discarded as burn-in. Estimates of hybrid frequencies were based on individual probabilities of having ancestry in populations other than the source population. The comparisons between conspecific populations were used as a control to assure that the analyses had sufficient power in assigning individuals to different clusters given the observed levels of genetic differentiation between populations. More recent and potentially ongoing geneflow between conspecific populations should generally result in more ambiguous assignments of individuals to populations as compared to genetically isolated heterospecific populations, irrespective of whether these occur in sympatry or not. We used the program DISTRUCT 1.1 [60] to graphically display STRUCTURE results (Figure 4).
Second, we used the assignment methods in the program GENECLASS2 [61] to estimate the likelihood of origin for each individual in each potential source population. All four populations were analyzed in a single dataset. To calculate likelihoods, we chose a Bayesian criterion with a Dirichlet prior distribution for allele frequencies [62] using the resampling method of Paetkau et al. [63]. The number of simulated individuals for probability computation was set at 10,000.

\section{Acknowledgements}

We thank Washington Njagi, Abio Gafo, and Jairus Analo for assistance in the field. We are grateful to the Kenya Wildlife Service, the Kenya Forest Service, and the National Museums of Kenya for their support and for granting us access to the forest reserves. We are grateful to Frank E. Rheindt for helpful comments on the manuscript. Funding was provided by the Danish National Research Foundation, the Alexander von Humboldt Foundation, the Critical Ecosystem Partnership Fund, the Cusanuswerk, the International School of Biodiversity Sciences, Denmark, and the Harvard Society of Fellows. This publication was funded by the German Research Foundation (DFG) and the University of Wuerzburg in the funding programme Open Access Publishing.

\section{Author details}

${ }^{1}$ Centre for Social Evolution, Department of Biology, University of Copenhagen, Universitetsparken 15, 2100 Copenhagen, Denmark. 2Laboratory of Insect Social Evolution, The Rockefeller University, 1230 York Avenue, New York, NY 10065, USA. ${ }^{3}$ Zoological Research Museum Alexander Koenig, Adenauerallee 160, 53113 Bonn, Germany. ${ }^{4}$ Department of Animal Ecology and Tropical Biology, Biocenter, University of Würzburg, Am Hubland, 97074 Würzburg, Germany. ${ }^{5}$ Länderinstitut für Bienenkunde, Friedrich-Engels-Strasse 32, 16540 Hohen Neuendorf, Germany.

\section{Authors' contributions}

DJCK, MKP, CS, JJB designed the study an acquired funding. MKP and CS collected all army ant samples and identified them. DJCK and MKP conducted the molecular genetic studies and analysed the data. CS conducted the morphometric analyses. DJCK wrote the first version of the paper. All authors contributed to and approved the final manuscript.

\section{Authors' information}

DJCK is the head of the Laboratory of Insect Social Evolution at The Rockefeller University. He is broadly interested in the evolution of social insects, and army ants are his main study systems. MKP is a postdoctoral ecologist at the Department of Animal Ecology and Tropical Biology, University of Würzburg, Germany. He studies the ecology and conservation of tropical rainforest animals. CS is a postdoctoral fellow at the Länderinstitut für Bienenkunde in Hohen Neuendorf, Germany, where he presently works 
on honeybees. He has a long-standing interest in the ecology and evolution of African army ants. JJB is the director of the Centre for Social Evolution at the University of Copenhagen.

\section{Competing interests}

The authors declare that they have no competing interests.

Received: 16 May 2011 Accepted: 22 August 2011

Published: 22 August 2011

\section{References}

1. Rieseberg LH: Hybrid origins of plant species. Annu Rev Ecol Syst 1997, 28:359-389.

2. Dowling $\mathrm{TE}$, Secor $\mathrm{CL}$ : The role of hybridization and introgression in the diversification of animals. Annu Rev Eco Syst 1997, 28:593-619.

3. Seehausen O: Hybridization and adaptive radiation. Trends Ecol Evol 2004, 19:198-207.

4. Mallet J: Hybrid speciation. Nature 2007, 446:279-283.

5. Mavárez J, Linares M: Homoploid hybrid speciation in animals. Mol Ecol 2008, 17:4181-4185.

6. Burke JM, Arnold ML: Genetics and the fitness of hybrids. Annu Rev Genet 2001, 35:31-52.

7. Taylor EB, Boughman JW, Groenenboom M, Sniatynski M, Schluter D, Gow JL: Speciation in reverse: morphological and genetic evidence of the collapse of a three-spined stickleback (Gasterosteus aculeatus) species pair. Mol Ecol 2006, 15:343-355.

8. Anderson KE, Linksvayer TA, Smith CR: The causes and consequences of genetic caste determination in ants (Hymenoptera: Formicidae). Myrmecol News 2008, 11:119-132.

9. Schwander T, Lo N, Beekman M, Oldroyd BP, Keller L: Nature versus nurture in social insect caste differentiation. Trends Ecol Evol 2010, 25:275-282.

10. Umphrey GJ: Sperm parasitism in ants: selection for interspecific mating and hybridization. Ecology 2006, 87:2148-2159.

11. Feldhaar $\mathrm{H}$, Foitzik $\mathrm{S}$, Heinze J: Lifelong commitment to the wrong partner: hybridization in ants. Philos T R Soc B 2008, 363:2891-2899.

12. Van der Have TM, Pedersen JS, Boomsma JJ: Mating, hybridisation and introgression in Lasius ants (Hymenoptera, Formicidae). Myrmecological News 2010, 15:109-115.

13. Volny VP, Gordon DM: Genetic basis for queen-worker dimorphism in a social insect. Proc Natl Acad Sci USA 2002, 99:6108-6111.

14. Helms Cahan SH, Keller L: Complex hybrid origin of genetic caste determination in harvester ants. Nature 2003, 424:306-309.

15. Kulmuni J, Seifert B, Pamilo P: Segregation distortion causes large-scale differences between male and female genomes in hybrid ants. Proc Natl Acad Sci USA 2010, 107:7371-7376.

16. Kronauer DJC, Schöning C, Vilhelmsen L, Boomsma JJ: A molecular phylogeny of Dorylus army ants provides evidence for multiple evolutionary transitions in foraging niche. BMC Evol Biol 2007, 7:56.

17. Kronauer DJC, Schöning C, Pedersen JS, Boomsma JJ, Gadau J: Extreme queen-mating frequency and colony fission in African army ants. $\mathrm{Mol}$ Ecol 2004, 13:2381-2388.

18. Berghoff SM, Kronauer DJC, Edwards KJ, Franks NR: Dispersal and population structure of a New World predator, the army ant Eciton burchellii. J Evolution Biol 2008, 21:1125-1132.

19. Kronauer DJC, Schöning C, d'Ettorre P, Boomsma JJ: Colony fusion and worker reproduction after queen loss in army ants. Proc Roy Soc B 2010, 277:755-763.

20. Franks NR, Hölldobler B: Sexual competition during colony reproduction in army ants. Biol J Linn Soc 1987, 30:229-243.

21. Schöning C, Kinuthia W, Boomsma JJ: Does the afrotropical army ant Dorylus (Anomma) molestus go extinct in fragmented forests? J East Afr Nat Hist 2006, 95:163-179.

22. Peters MK, Okalo B: Severe declines of ant-following birds in African rainforest fragments are facilitated by a subtle change in army ant communities. Biol Conserv 142:2050-2058.

23. Peters MK, Fischer G, Schaab G, Kraemer M: Species compensation maintains abundance and raid rates of African swarm-raiding army ants in rainforest fragments. Biol Conserv 2009, 142:668-675.

24. Raignier A, Van Boven JKA, Ceusters R: Der Polymorphismus der afrikanischen Wanderameisen unter biometrischen und biologischen
Gesichtspunkten. In Sozialpolymorphismus bei Insekten. Probleme der Kastenbildung im Tierreich. Edited by: Schmidt GH. Stuttgart: Wissenschaftliche Verlagsgesellschaft; 1974:668-693.

25. Wasmann E: Neue Anpassungstypen bei Dorylinengästen Afrikas (Col. Staphylinidae). (218. Beitrag zur Kenntnis der Myrmekophilen.). Zeitschr Wissenschaftl Zool 1917, 17:257-360.

26. Ballard JWO, Whitlock MC: The incomplete natural history of mitochondria. Mol Ecol 2004, 13:729-744.

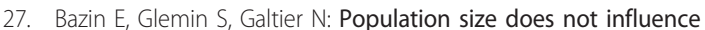
mitochondrial genetic diversity in animals. Science 2006, 312:570-572.

28. Bintanja R, Van de Wal RSW, Oerlemans J: Modelled atmospheric temperatures and global sea levels over the past million years. Nature 2005, 437:125-128.

29. Caputo R: Sea-level curves: perplexities of an end-user in morphotectonic applications. Global Planet Change 2007, 57:417-423.

30. Wagner P, Köhler J, Schmitz A, Böhme W: The biogeographical assignment of a west Kenyan rain forest remnant: further evidence from analysis of its reptile fauna. J Biogeogr 2008, 35:1349-1361.

31. Moreau RE: Pleistocene climatic changes and the distribution of life in East Africa. J Ecol 1933, 21:415-435.

32. Mahaney WC: Quaternary and environmental research on East African mountains Rotterdam: AA. Balkema; 1989.

33. Hilgenboecker $K$, Hammerstein $P$, Schlattmann P, Telschow A, Werren JH: How many species are infected with Wolbachia? - a statistical analysis of current data. FEMS Microbiol Let 2008, 281:215-220.

34. Bachtrog D, Thornton K, Clark A, Andolfatto P: Extensive introgression of mitochondrial DNA relative to nuclear genes in the Drosophila yakuba species group. Evolution 2006, 60:292-302.

35. Powell J: Interspecific cytoplasmic gene flow in the absence of nuclear gene flow: evidence from Drosophila. Proc Natl Acad Sci USA 1983, 80:492-495.

36. Roca A, Georgiadis N, O'Brien S: Cytonuclear genomic dissociation in African elephant species. Nat Genet 2005, 37:96-100.

37. Linnen CR, Farrell BD: Mitonuclear discordance is caused by rampant mitochondrial introgression in Neodiprion (Hymenoptera: Diprionidae) sawflies. Evolution 2007, 61:1417-1438.

38. Koevoets T, Beukeboom LW: Genetics of postzygotic isolation and Haldane's rule in haplodiploids. Heredity 2009, 102:16-23.

39. Berthier P, Excoffier L, Ruedi M: Recurrent replacement of mtDNA and cryptic hybridization between two sibling bat species Myotis myotis and Myotis blythii. Proc Roy Soc B 2006, 273:3101-3109.

40. Joly S, McLenachan PA, Lockhart PJ: A statistical approach for distinguishing hybridization and incomplete lineage sorting. Am Nat 2009, 174:E54-E70.

41. Schoville SD, Roderick GK: Evolutionary diversification of cryophilic Grylloblatta species (Grylloblattodea: Grylloblattidae) in alpine habitats of California. BMC Evol Biol 2010, 10:163.

42. Ross KG, Gotzek D, Ascunce MS, Shoemaker DD: Species delimitation: a case study in a problematic ant taxon. Syst Biol 2010, 59:162-184.

43. Seifert B, Kulmuni J, Pamilo P: Independent hybrid populations of Formica polyctena X rufa wood ants (Hymenoptera: Formicidae) abound under conditions of forest fragmentation. Evol Ecol 2010, 24:1219-1237.

44. Kronauer DJC, Schöning C, Boomsma JJ: Male parentage in army ants. Mol Ecol 2006, 15:1147-1151.

45. Gotwald WH, Schaefer RF: Taxonomic implications of doryline worker ant morphology: Dorylus subgenus Anomma (Hymenoptera: Formicidae). Sociobiology 1982, 7:187-204.

46. Gotwald WH: Predatory behavior and food preferences of driver ants in selected African habitats. Ann Entomol Soc Am 1974, 67:877-886.

47. Schöning C, Kinuthia W, Franks NR: Evolution of allometries in the worker caste of Dorylus army ants. Oikos 2005, 110:231-240.

48. Schöning C, Humle T, Möbius Y, McGrew WC: The nature of culture: technological variation in chimpanzee predation on army ants revisited. J Hum Evol 2008, 55:48-59.

49. Simon C, Frati F, Beckenbach A, Crespi B, Liu H, Flook P: Evolution, weighting, and phylogenetic utility of mitochondrial gene sequences and a compilation of conserved polymerase chain reaction primers. Ann Entomol Soc Am 1994, 87:651-701.

50. Kronauer DJC, Boomsma JJ, Gadau J: Microsatellite markers for the driver ant Dorylus (Anomma) molestus. Mol Ecol Notes 2004, 4:289-290. 
51. Huelsenbeck JP, Ronquist F: MRBAYES: Bayesian inference of phylogeny. Bioinformatics 2001, 17:754-755.

52. Ronquist F, Huelsenbeck JP: MRBAYES 3: Bayesian phylogenetic inference under mixed models. Bioinformatics 2003, 19:1572-1574.

53. Zwickl DJ: Genetic algorithm approaches for the phylogenetic analysis of large biological sequence datasets under the maximum likelihood criterion. PhD thesis The University of Texas at Austin; 2006.

54. Nylander JAA: MrModeltest v2. Program distributed by the author Evolutionary Biology Centre, Uppsala University; 2004

55. Templeton AR, Crandall KA, Sing CF: A cladistics analysis of phenotypic associations with haplotypes inferred from restriction endonuclease mapping and DNA sequence data III. Cladogram estimation. Genetics 1992, 132:619-633.

56. Clement M, Posada D, Crandall KA: TCS: a computer program to estimate gene genealogies. Molecular Ecology 2000, 9:, 1657-1659.

57. Goudet J: FSTAT, a program to estimate and test gene diversities and fixation indices (version 2.9.3.2).[http://www2.unil.ch/popgen/softwares/ fstat.htm].

58. Pritchard JK, Stephens M, Donnelly P: Inference of population structure using multilocus genotype data. Genetics 2000, 155:945-959.

59. Falush D, Stephens M, Pritchard JK: Inference of population structure: Extensions to linked loci and correlated allele frequencies. Genetics 164:1567-1587.

60. Rosenberg NA: DISTRUCT: a program for the graphical display of population structure. Mol Ecol Notes 2004, 4:137-138.

61. Piry S, Alapetite A, Cornuet JM, Paetkau D, Baudouin L, Estoup A: GENECLASS2: A software for genetic assignment and first-generation migrant detection. J Hered 2004, 95:536-539.

62. Rannala B, Mountain JL: Detecting immigration by using multilocus genotypes. Proc Natl Acad Sci USA 1997, 94:9197-9201.

63. Paetkau D, Slade R, Burden M, Estoup A: Genetic assignment methods for the direct, real-time estimation of migration rate: a simulation-based exploration of accuracy and power. Mol Ecol 2004, 13:55-65.

doi:10.1186/1742-9994-8-20

Cite this article as: Kronauer et al: Hybridization in East African swarmraiding army ants. Frontiers in Zoology 2011 8:20.

\section{Submit your next manuscript to BioMed Central} and take full advantage of:

- Convenient online submission

- Thorough peer review

- No space constraints or color figure charges

- Immediate publication on acceptance

- Inclusion in PubMed, CAS, Scopus and Google Scholar

- Research which is freely available for redistribution

Submit your manuscript at www.biomedcentral.com/submit
Biomed Central 